\title{
Adventive and invasive plant species of natural ecosystems in the Republic of Khakassia
}

\author{
E. G. Lagunova ${ }^{* 1}$, E. S. Ankipovich ${ }^{1}, D . N$. Shaulo $^{2}$ \\ ${ }^{1}$ Katanov Khakassia State University, 655017 Abakan, Russia \\ ${ }^{2}$ Central Siberian Botanical Garden SB RAS, 630090 Novosibirsk, Russia
}

\begin{abstract}
In this study, 56 adventive species have been identified in Khakas flora to date. In terms of the introduction method, xenophytes dominate; this group is composed of 44 species, which is $78.6 \%$ of all the adventive species under study. The ergasiophyte group consists of 12 species $(21.4 \%)$. According to the naturalization degree, we identified three groups: epecophytes, agriophytes, and ephemerophytes. The epecophyte group is in the lead and consists of 21 species (37.5\%). The agriophytes are represented by 19 invasive species (33.9\%). The ephemerophyte group is composed of 16 species (28.6\%). Thus, the ratios of the synanthropic-plant groups defined according to the introduction method and naturalization degree indicate that most of these adventive plants have been introduced unintentionally and successfully established themselves on a territory new to them. The adventive fraction of natural ecosystems in Khakas flora contains 20 species included in the report "The Black Book of the Flora of Siberia" [1].
\end{abstract}

Khakas wild life is currently experiencing a powerful impact of the human factor, which is represented not only by agricultural and industrial development of the territory but also by annually increasing substantial recreational use. This is especially true for the territories near lake basins (lakes Shira, Itkul, Belyo, and Tus). Undoubtedly, these processes affect the structure and composition of the flora of these unique places, and in particular, lead to an increase in the number and abundance of alien (adventive and invasive) plant species. Human economic activities cause large-scale and often irreversible changes in flora and natural phytocenoses; in this regard, investigation into the processes of anthropogenic transformation of flora is an important field of modern botanical research.

As a consequence of the anthropogenic impact on natural ecosystems, the process of flora synanthropization is rapidly strengthening, thereby forming a new natural and anthropogenic environment. The emergence of adventive species in the flora is related primarily to economic and household activities of humans. The main method of distribution of alien species is their introduction along with the seeds of cultivated plants that have spread far beyond their original geographic range, and other methods include human importation of the seeds and various planting materials from other locations and

\footnotetext{
*Corresponding author: lglagunova@mail.ru
} 
introduction via vehicle transport and with various goods. The adventive fraction combines species that have been brought into the study area accidentally and the species that have been seeded here intentionally, i.e., introduced. The adventive fraction of the flora is a special component that is highly dynamic in comparison with the native fraction.

Our study showed that in Khakas flora, the naturalization of alien (adventive or introduced) plant species often occurs in disturbed habitats (e.g., in towns and villages, near roads, at unauthorized dumps of household waste, in fields, vegetable gardens, and floodplain sand and pebble deposits) and on fallow lands in steppe hollows of Khakassia.

Plant samples stored in well-known collection funds (NS, TK, KRAS, and HGU) and literary data were used to study the adventive species of Khakassia. According to the approach proposed by N. G. Ilminskih [2], among cultivated plants, only those were taken into account that show tendencies toward independent seed-based or vegetative renewal. Field research allowed us to identify adventive species and to clarify the details of their modern distribution.

In this study, 56 adventive species have been identified in Khakas natural ecosystems to date. While investigating the adventive fraction of the flora, we relied on the classifications proposed by J. A. Kornas [3], F. G. Schroeder [4], V. V. Protopopova [5], A. I. Pyak [6] and G. S. Antipina [7].

The most important characteristics of the adventive fraction are the introduction method and naturalization degree. It must be mentioned that we employed only these two principles: the introduction method and naturalization degree.

In the adventive fraction of the flora of Khakas natural ecosystems, xenophytes dominate among the groups defined by the method of introduction; they consist of 44 species, which is $78.6 \%$ of all the adventive species being analyzed. The xenophyte group includes species introduced into natural communities unintentionally, i.e., via various human activities. The reason for such a widespread distribution of xenophytes is that only a few of the introduced species that are used in landscaping and in household plots (and are very widespread in Khakas towns) can spread independently and become members of natural and seminatural communities. The xenophytes include Hordeum jubatum L., Amaranthus retroflexus L., Sisymbrium volgense M. Bieb., Dontostemon pinnatifidus (Willd.) Al-Shehbaz et H.Ohb., Atriplex tatarica L., A. sagittata Borkh., Impatiens glandulifera Royle., Epilobium adenocaulon Hausskn., Oenothera villosa Thunb., Elisanthe noctiflora (L.) Rupr., Silene dichotoma Ehrh., Chrysaspis campestris (Schreb.) Desv., Medicago $\times$ varia T. Martyn., Nepeta cataria L., Phacelia tanacetifolia Benth., and Echinops sphaerocephalus L.

The identified ergasiophytes are represented by 12 species $(21.4 \%)$; they have been introduced deliberately. This group mainly consists of trees and shrubs: Ulmus pumila L., Ribes aureum Pursh, R. diacanthum Pall., Cerasus fruticosa Pall., C. tomentosa (Thunb.) Yas. Endo, Malus baccata (L.) Borkh., Physocarpus opulifolius (L.) Maxim., and Populus balsamifera L. This group also includes species that have "escaped" from cultivation and have spread in various phytocenoses or anthropogenically disturbed locations: Helianthus tuberosus L., Cosmos bipinnatus Cav., Asparagus officinalis L., and Armoracia rusticana P.G. Gaertn., B. Mey. \& Scherb.

According to the naturalization degree, we identified three groups: epecophytes, agriophytes, and ephemerophytes.

The epecophytes are in the lead and are represented by 21 species (37.5\%). These are alien species that have settled in disturbed, mainly synanthropic habitats: along roadsides, along railway embankments, in dumps, slag-heaps, fallow lands, and in the vicinity of towns and villages [Echinochloa crus-galli (L.) Beauv., Setaria viridis L., Elsholtzia ciliata (Thunb.) Hylander., Atriplex sagittata, S. volgense, Senecio viscosus L., E. sphaerocephalus, P. opulifolius, and other species]. 
The agriophytes are represented by 19 invasive species (33.9\%) that have become fullfledged members of natural communities. Among them, one can distinguish a subgroup of species that have naturalized to date, which includes some plants that have become widespread and sometimes are already regarded as native species of the local flora. This subgroup contains such species as $H$. jubatum, Panicum miliaceum L., Fagopyrum esculentum Moench, E. adenocaulon, R. aureum, M. baccata, Elodea canadensis Michx., Pastinaca sativa L., and Conyza canadensis (L.) Cronquis.

Ephemerophytes are fluctuating species, which appear and disappear in local habitats every now and then. As a rule, in our study, they were found to be annual or biennial plants that settle in disturbed habitats (A. tatarica, I. glandulifera Royle., A. retroflexus, D. pinnatifidus, C. campestris, and other species). This group also includes species that, despite the impossibility of naturalization, are quite common on synanthropized territories owing to constant inflow of seeds. This subgroup is represented by ornamental plants (C. bipinnatus and A. officinalis) and by agricultural and garden plants (Portulaca oleracea L., $P$. tanacetifolia, H. tuberosus, and F. esculentum Moench). The ephemerophyte group consists of 16 species, which is $28.6 \%$ of all the adventive species under study.

Thus, the ratios of the synanthropic-plant groups defined according to the introduction method and naturalization degree show that most of the adventive plants have been introduced unintentionally and successfully established themselves on a territory new to them.

Some of these species are characterized by active infiltration of local plant communities where a native member of the flora is ousted. Such plants are classified as invasive: aggressive alien species that spread as a result of direct or indirect human influence, produce offspring in very large numbers, and become distributed over a considerable distance from parental individuals. The spread of invasive species causes significant damage to agriculture, forestry, and water management and has a negative effect on overall biodiversity of ecosystems.

Because alien species can theoretically pose a threat to local ecosystems, there is a need for frequent monitoring of their status. Therefore, at present, the problem that is coming to the fore is the identification of the main stages in the evolution of the biological invasions caused by the most aggressive alien plant species.

The adventive fraction of natural ecosystems in the Khakas flora contains 20 species included in the report "The Black Book of the Flora of Siberia" [1].

Eleven of them are potentially invasive plants that are capable of renewal at introduction sites and have manifested themselves as invasive species in adjacent regions [E. crus-galli, A. sagittata, E. adenocaulon, Epilobium pseudorubescens A. Skvorts., O. villosa, Lotus corniculatus L., Acer negundo, Sphallerocarpus gracilis (Besser ex Trevir.) Koso-Pol., P. sativa, H. tuberosus, and Centaurea pseudomaculosa Dobrocz.].

In addition, four are alien species currently spreading and naturalizing in disturbed habitats; in the course of further naturalization, some of them will be able to infiltrate seminatural and natural communities. This subgroup consists of I. glandulifera, Echinocystis lobata (Michx.) Torr. et Gray., M. baccata, and E. canadensis.

Four other species (U. pumila, A. rusticana, E. ciliata, and C. canadensis) actively penetrate into natural and seminatural communities, change the appearance of ecosystems, disrupt succession relations, act as edificators and dominants forming large areas of singlespecies thickets, and can displace native species of the flora.

H. jubatum is actively spreading and naturalizing. This is an East Asian and North American species with a secondary geographic range in temperate regions of the planet and is actively spreading across the regions of Western and Central Siberia. In Khakassia, it forms thickets in disturbed, seminatural, and natural habitats. It is ubiquitous in the steppe zone. 


\section{References}

1. The Black Book of the Flora of Siberia (Novosibirsk, Geo, 2016)

2. N. G. Ilminskih, Florogenesis in an urbanized environment (on the example of the cities of the Vyatka-Kama region) (Leningrad, 1993)

3. J. A. Kornas, Mater. Zakl. Fitisocjol. Stosowanej U.W. 25 (1968)

4. F. G. Schroëder, Vegetatio, 16 (1969)

5. V. V. Protopopova, Synanthropic flora of Ukraine and ways of its development (Kiev, 1991)

6. A. I. Pyak, Botanical Journal, 11 (1994)

7. G. S. Antipina, Urbanoflora of Karelia (Petrozavodsk, 2002) 